\title{
FAILURE MECHANISM ANALYSIS CONSIDERS THE HYDROLOGICAL AND SEISMIC CONDITIONS AT CHASHAN SITE IN CENTRAL TAIWAN
}

\author{
M. C. Chung ${ }^{1 *}$, C. H. Chen ${ }^{1}$, T. L. Tai ${ }^{2}$, M. M. Chen ${ }^{2}$ \\ ${ }^{1}$ Geotechnical Engineering Research Center, Sinotech Engineering Consultants, Inc., Taipei City, Taiwan, R.O.C. - \\ (mcchung, chchen)@sinotech.org.tw \\ ${ }^{2}$ Environmental \& Engineering Geology Division, Central Geological Survey, M. O. E. A., New Taipei City, Taiwan, R.O.C. - \\ (tunglin, chenmm)@moeacgs.gov.tw
}

KEY WORDS: Large-scale Landslide, Failure Mechanism, Hydrological, Seismic, Scenario Simulation

\begin{abstract}
:
The investigation results of large-scale landslides in the central part of Taiwan from Central Geologic Survey identified a new, largescale landslide in the Chashan Village of Alishan Township, Chiayi County (ID: D160) which has the potential to influence the safety of Chashan Village residents. In coordination with the surface geological survey, Chashan site can be divided into three potential sliding areas (zones A, B and C). The paper uses GeoStudio for evaluating the stability of different hydrological and seismic scenarios. The results of scenario simulation show that: (1) In the normal and high water level scenarios, the safety factor obtained in zone A is greater than 1.0, and the initial judgment belongs to the stable state; (2) In the earthquake scenarios, the A4 potential sliding mass in zone A will be collapsed; (3) Through the scenario simulation, when the water level in zone A rises more than 25 meters or the PGA exceeds 160 gal, it is possible to cause the collapse of A4 potential sliding mass. The result of the study will contribute that the complex phenomenon between the stability of landslides and hydrogeological conditions can be revealed and clarified through the detailed study on the hydrogeological investigation, observation and the numerical simulation.
\end{abstract}

\section{INTRODUCTION}

Taiwan is an active mountain belt created by the oblique collision between the northern Luzon arc and the Asian continental margin. The inherent complexity of geological nature creates numerous discontinuities through rock masses and relatively steep hillside on this island. In recent years, the increase in the frequency and intensity of extreme natural events due to climate change brought significant large-scale landslides in the mountain area of Taiwan. Because of the extreme volume of material mobilized in a large-scale landslide, other natural disasters can be triggered by the large-scale landslide including debris flows and landslide dams. Also, transportation systems can be severed and structures buried. Therefore, large-scale landslides can severely impact and pose a significant hazard to nearby villages. This study is aimed to better understand the mechanism of triggering landslide hazards so that casualties and property damages can hopefully be reduced in the occurrence probability of natural disasters in the future through the appropriate disaster prevention planning we proposed.

Through a long term project implemented by the Central Geological Survey (CGS, 2010-2012; 2013-2015), the location of potential large-scale landslides and villages more susceptible to large-scale landslide hazards have been mapped. The CGS concluded that a potential large-scale landslide in the Chashan Village of Alishan Township, Chiayi County, (ID: D160, hereby called the Chashan site, Figure 1) may impact the safety of the Chashan Village. According to household registration office census data in January, 2018 (data source: https://chuchihro.cyhg.gov.tw), there were a total of 112 households and 297 people in the Chashan Village.
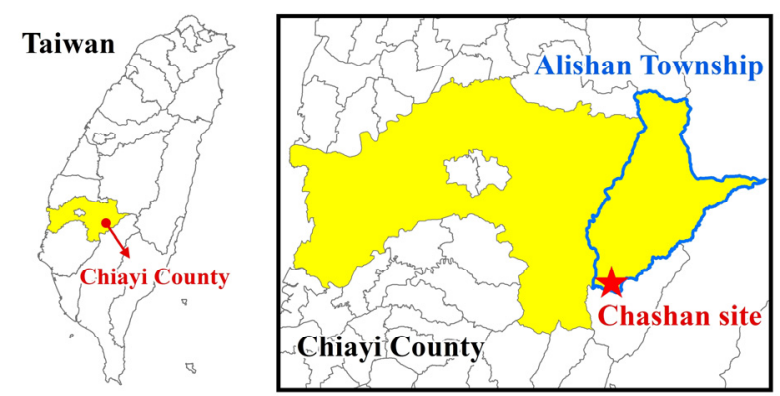

Figure 1. Location of the Chashan site

\section{HYGROGEOLOGICAL} INVESTIGATIONS

\subsection{Regional geology and geological survey}

According to a 1/50,000 geologic map (Central Geological Survey, Figure 2), the Chashan site is located in the Changchihkeng Formation. The Changchihkeng Formation is a thick sequence of dark gray shale and light gray fine-grained sandstone containing an assemblage of varied marine faunas. The sandstone is dense, compact, and partly calcareous subgraywacke, locally containing carbonaceous matter and broken plant remains. No white sandstone or coal beds have been found. The shale is very compact and slightly indurated (data source: https://www.moeacgs.gov.tw/english/twgeol/ twgeol western 23.jsp). On the west side of the Chashan site are the Sinvi anticline and Laitou fault, while the Laitou fault is the most important geological structure adjacent to the site. The slopes of the Chashan site are mostly $40 \%-55 \%$ and more than

* Corresponding author 
$55 \%$; the central and west sides of the site are south-facing and south-facing slopes, while the eastern side is the west-facing and south-facing slopes. According to field survey, the joints in this site are mainly in two groups: the joint attitude (dip/dip direction) are 58/270 and 70/175 respectively.

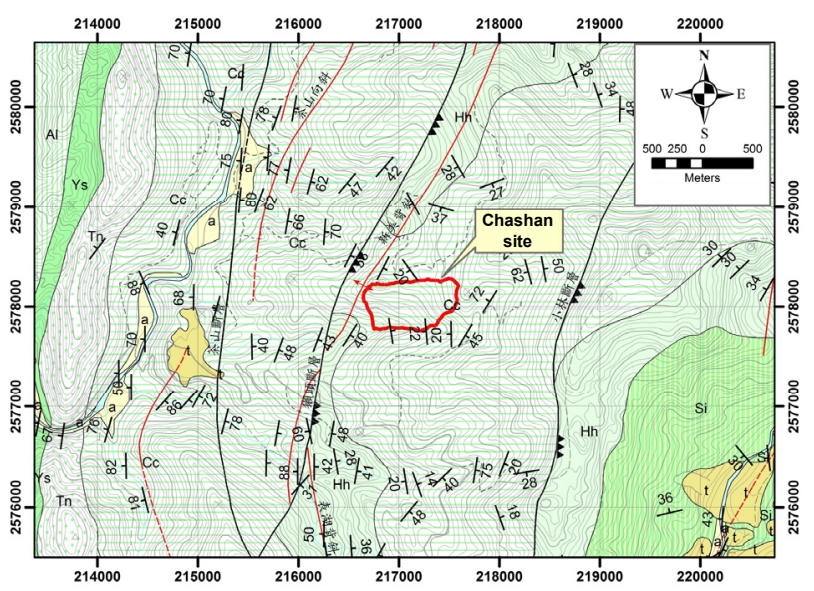

Figure 2. Regional geological map of the Chashan site

Through data collection and multi-period aerial photo, the study can find out the site status, topographic changes, collapse history and regional linear distribution of the survey sites. In addition, in coordination with the surface geological survey (including regional survey and site survey), the Chashan site can be divided into three potential sliding areas (zones A, B and C), the surface geological map shown in Figure 3.

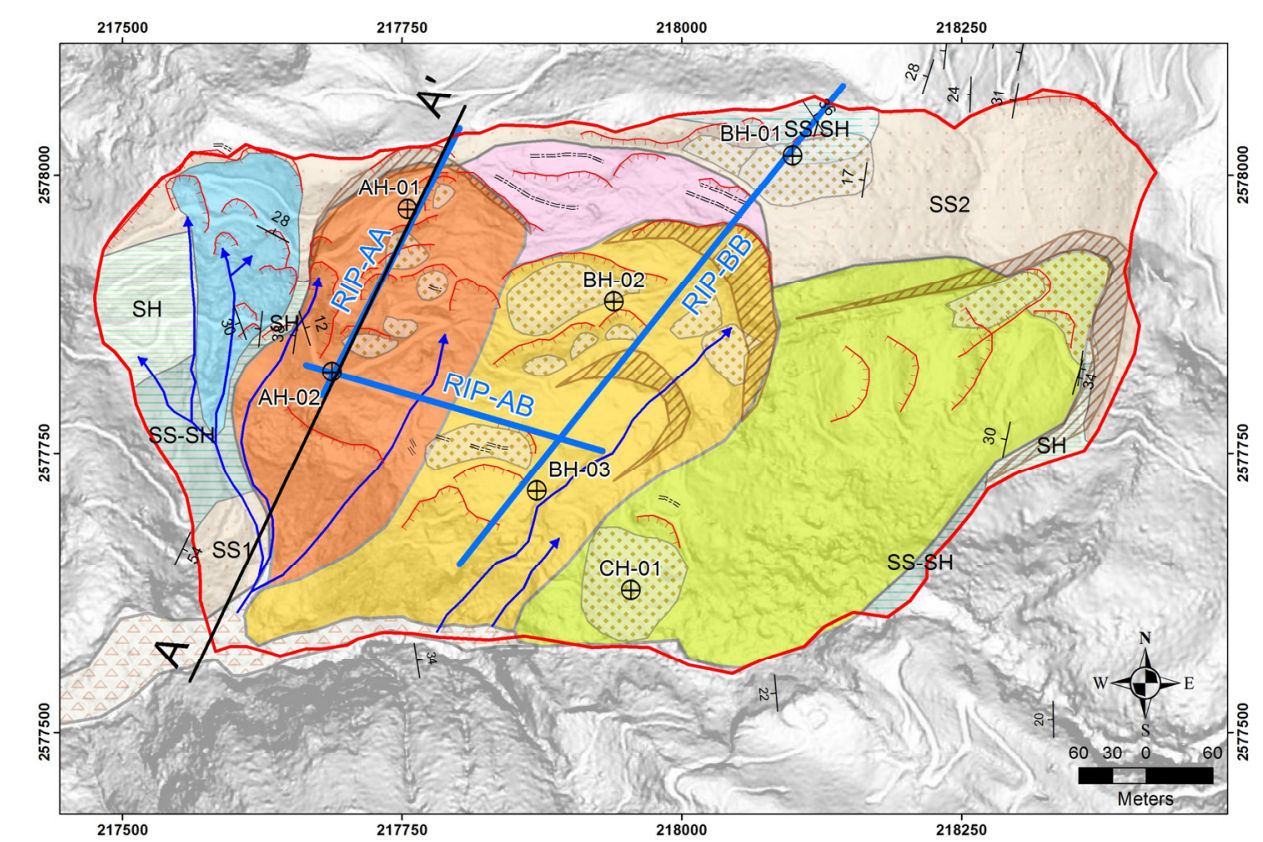

$\oplus$ Borehole 1 Attitude of rock outcrop Analysis profile RIP line $\longrightarrow$ Erosion ditch Tension crack C. Collapse crown Chashan site Zone A Zone B Zone C Shallow cliffs Shallow collapse area Deposition area Tension cracks area Gully erosion area $\mathrm{SS} / \mathrm{SH}$ SS2 $\mathrm{SH}$ SS-SH SS1

Figure 3. Surface geological map of the Chashan site
According to the above results, it can be applied to establish the geological profile shown as Figure 6 and the hydrogeological parameters of each formation. This paper will focus on zone A, there are four potential sliding masses. It is recommended to assess the different conditions of the potential sliding mass, and pay attention to its activity.

\begin{tabular}{|c|c|c|c|}
\hline \multirow{2}{*}{ Borehole } & \multicolumn{2}{|c|}{ Coordinates (TWD97) } & Borehole depth \\
\cline { 2 - 3 } & $\mathrm{E}$ & $\mathrm{N}$ & $(\mathrm{m})$ \\
\hline AH-01 & 217754 & 2577964 & 50 \\
AH-02 & 217690 & 2577817 & 50 \\
BH-01 & 218098 & 2578014 & 32 \\
BH-02 & 217943 & 2577886 & 60 \\
BH-03 & 217865 & 2577719 & 68 \\
CH-01 & 217949 & 2577626 & 60 \\
\hline
\end{tabular}

Table 1. Borehole drilling date of the Chashan site 


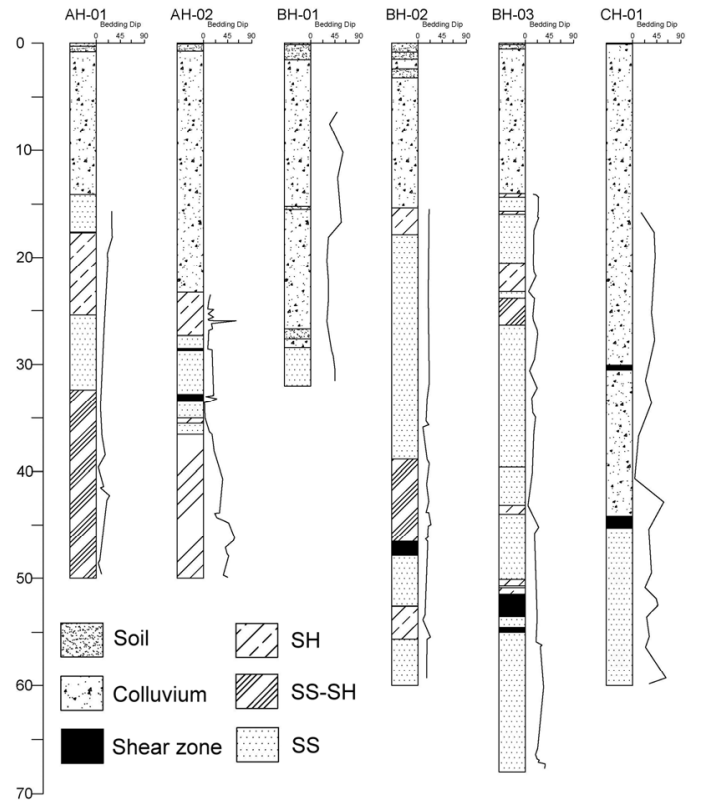

Figure 4. Borehole columnar section

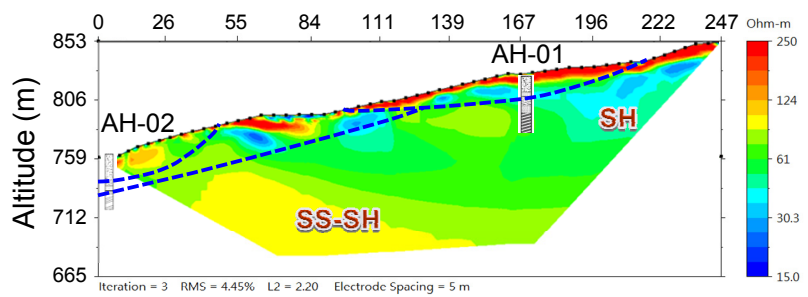

Figure 5. Illustration of geophysics survey and geologic borehole investigation results (RIP-AA)

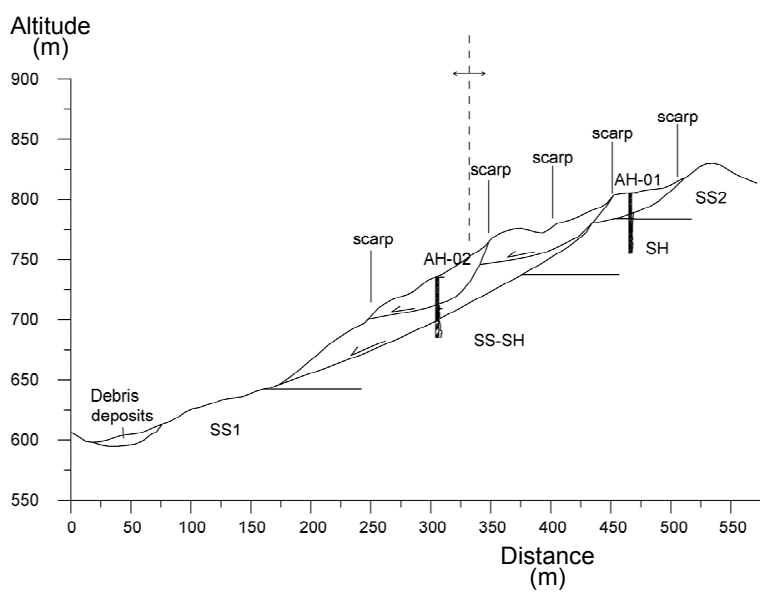

Figure 6. Geological profile of the Chashan site (along AA' line in Figure 3)

\subsection{In-situ monitoring system}

The monitoring system set up in the Chashan site included: one set of rain-gauge (D160), two sets of soil moisture meter installed nearby $\mathrm{AH}-01$ and $\mathrm{BH}-03$, two observation wells installed in $\mathrm{AH}-02$ and $\mathrm{BH}-03$, two time-domain reflectometers (TDR) installed in AH-01 and BH-02, and five sets of strong motion recorders installed in CS-01 CS-05. The investigation simultaneously recorded rainfall, soil moisture content, groundwater levels, underground deformation, and ground motion at the Chashan site. The layout and design of monitoring system at the CHashan site are shown in Figure 7.

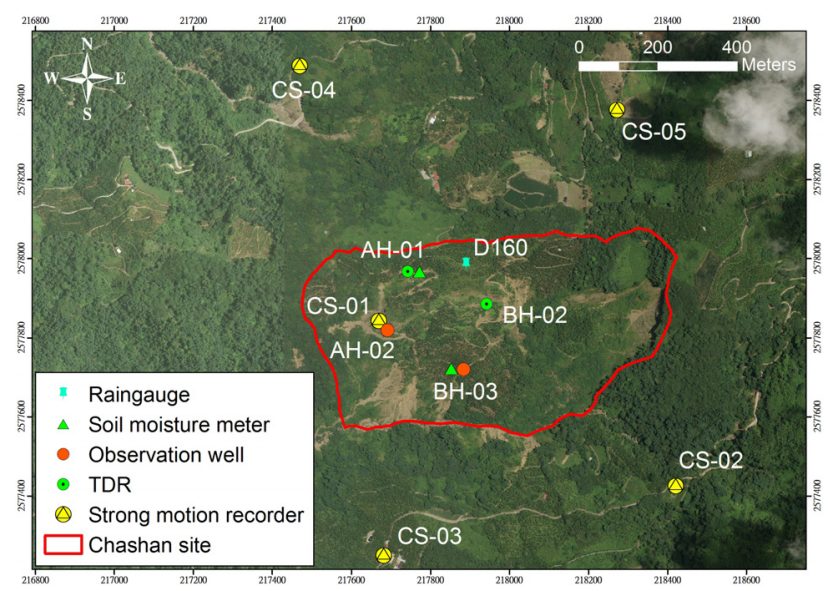

Figure 7. Layout of monitoring system at the Chashan site

The monitoring period is from June 15, 2017 to November 30, 2017. The observed records and key results are summarized below:

1. The precipitation amount of $1,763 \mathrm{~mm}$ was recorded during the monitoring period at the Chashan site. Rainfall in the area during Typhoon NESAT (July 28-30) and HAITANG (July 29-31) was recorded as $573.5 \mathrm{~mm}$. The greatest daily rainfall was on July 31, with $246.5 \mathrm{~mm}$.

2. The underground observation system installed in September 2017, no significant rainfall events occurred until November 30, 2017. The maximum change of groundwater level in $\mathrm{AH}-01$ was about 0.5 meters and the maximum change of volumetric water content nearby AH-01 was about $3 \%$. The shear cable waveform of TDR has no significant difference in the change, indicating no signs of sliding during the observation period.

3. The ground motion observation system successfully recorded typhoon and seismic event signals during the observation time, such as Typhoon NESAT (July 28-30), Typhoon HAITANG (July 29-31), Chiayi Earthquake (July 30, M4.2), Taitung Earthquake (November 4, M5.3), and Chiayi Earthquake (November 22, M5.5). The magnitude of latter two earthquakes larger than 5 resulted in a significant ground motion (seismic intensity $>3$ ) at the Chashan site. Simultaneous observations of surface and subsurface observation data showed that the above events did not cause obvious coseismic surface and subsurface displacements at the Chashan site.

\section{CASE STUDY}

\subsection{Hydrogeological conceptual model}

The numerical geological model was established using a $6 \mathrm{mx}$ 6m Digital Elevation Model (DEM) of the Chashan site. This analysis profile starts from the top of the crest line and passes through boreholes $\mathrm{AH}-01$ and $\mathrm{AH}-02$, and then down to the bottom of the trench (Figure 8). The hydrogeological unit of this profile can be divided into five layers: which are $\mathrm{C}, \mathrm{SS} 1$, SS-SH, SH, and SS2. Morphometric and geotechnical analyses were carried out to the Chashan site through a series of in-situ and laboratory tests, the results of which were used as input for the modeling process. 


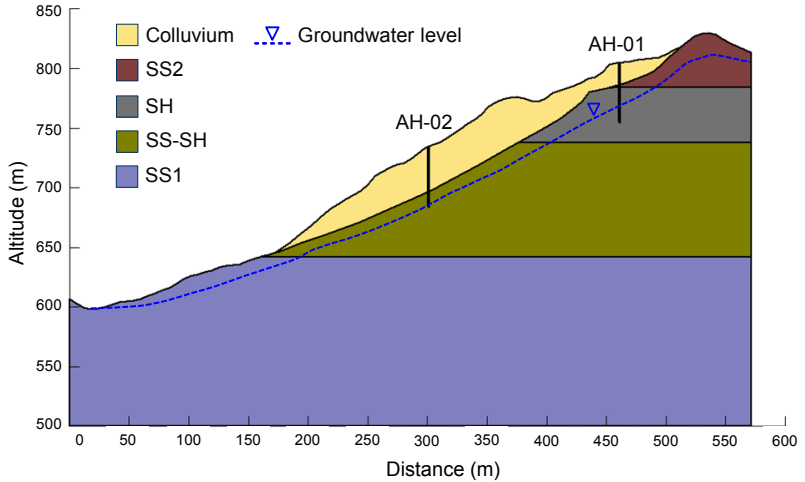

Figure 8. Hydrogeological conceptual model of the Chashan site

The boundary conditions of the hydrogeological conceptual model are shown in Figure 8. The left side boundary (RA) was set as a constant because a crest line had already been established. The right side boundary (SB) was set as a constant head boundary equal to the water table at the toe of the slope and adjacent drainage. The lower boundary (AB) was set as a no-flux boundary.

The reference values of parameters were obtained from the series of investigations and laboratory tests, and then further verified by the monitoring data observed from June 15, 2017 to November 30, 2017. This study first calibrated the hydraulic parameters by comparing data without measuring rainfall to the typical groundwater level for steady state seepage flow analysis. Using the above-mentioned procedure, parameters (Table 2) and groundwater level (Figure 8) of this site were determined, and the follow-up slope stability analysis was conducted.

\begin{tabular}{|c|c|c|c|}
\hline & $\begin{array}{c}\text { Unit weight } \\
\left(\mathrm{kN} / \mathrm{m}^{3}\right)\end{array}$ & $\begin{array}{c}\text { Cohesion } \\
\left(\mathrm{kg} / \mathrm{cm}^{2}\right)\end{array}$ & $\begin{array}{c}\text { Friction angle } \\
(\text { deg. })\end{array}$ \\
\hline $\mathrm{C}$ & 20 & 0.17 & 32.0 \\
$\mathrm{SS} / \mathrm{SH}$ & 25 & 17.00 & 30.0 \\
$\mathrm{SS} 2$ & 25 & 41.71 & 38.1 \\
$\mathrm{SH}$ & 25 & 9.03 & 23.5 \\
$\mathrm{SS}-\mathrm{SH}$ & 25 & 8.35 & 41.0 \\
$\mathrm{SS} 1$ & 25 & 41.71 & 38.1 \\
\hline
\end{tabular}

Note: Unit weight was obtained from soil classification tests; Cohesion and friction angle were obtained from direct shear test and triaxial test.

Table 2. Hydrogeological parameters of the Chashan site

\subsection{Scenario setting definition}

The setting of each scenario is as follows:

1. Normal condition

Steady-state water level is used as the water level and the effect of seismic force is not considered.

2. High water level condition

The highest water level during the monitoring period is taken as the water level and the effect of seismic force is not considered.

3. Earthquake condition

Steady-state water level is used as the water level and the seismic force is considered. The peak ground acceleration (PGA) adopts 0.28g (Construction and Planning Agency, 2011).

\subsection{Scenario simulation}

This study uses the GeoStudio software to perform slope stability analysis (Chung et al., 2017) on a two dimensional model of the Chashan site. In GeoStudio software, the limit equilibrium method module SLOPE/W was used. The factor of safety (F.S.) was assessed for various scenarios by entering groundwater level and PGA into the model. Therefore, the stability of each sliding mass under normal, high water level, and earthquake conditions is evaluated in the analysis.

After completing an analysis of the Chashan site along crosssection AA', four areas of potential sliding masses (A1 A4) were identified (Figure 9). In this study, in addition to analyzing the above four potential sliding masses, the function of "Auto Locate" built in GeoStudio is also used to automatically search for the sliding mass with the lowest F.S. The stability analyses of each of the masses are assessed for normal, high water level, and earthquake conditions. Results are shown in Table 3 and Figure 10-12. The results show that: (1) Analysis results reveal that of the five potential sliding masses, regardless of the scenario, the F.S. of Auto is lowest for the Zone A; (2) In the normal and high water level scenarios, the safety factor obtained in zone A is greater than 1.0, and the initial judgment belongs to the stable state; (3) In the earthquake scenarios, the A4 potential sliding mass in zone A will be collapsed.

The results in Table 3 show that zone A may collapse in the earthquake condition. In order to evaluate the potential collapse volume reasonably, the potential sliding mass obtained from Figure 12 is used in this study. With the aid of landslide microtopography, as shown in Figure 13, the calculated results show that the amount of collapse is $917,729 \mathrm{~m}^{3}$.

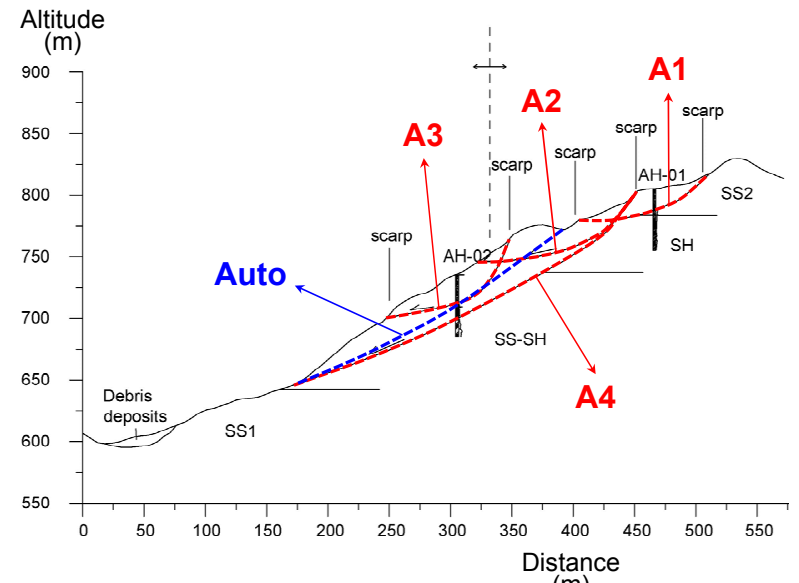

(m)

Figure 9. Geological profiles on the Chashan site (along AA' line in Figure 3)

\begin{tabular}{|c|c|c|c|c|c|}
\hline \multirow{2}{*}{ Scenario } & \multicolumn{5}{|c|}{ Potential sliding mass } \\
\cline { 2 - 6 } & $\mathrm{A} 1$ & $\mathrm{~A} 2$ & $\mathrm{~A} 3$ & $\mathrm{~A} 4$ & Auto \\
\hline Normal & 2.31 & 2.26 & 1.53 & 1.30 & 1.17 \\
High water level & 2.31 & 2.26 & 1.53 & 1.30 & 1.17 \\
Earthquake & 1.60 & 1.58 & 1.18 & 0.97 & 0.89 \\
\hline
\end{tabular}

Table 3. Analysis results of zone A in the Chashan site 


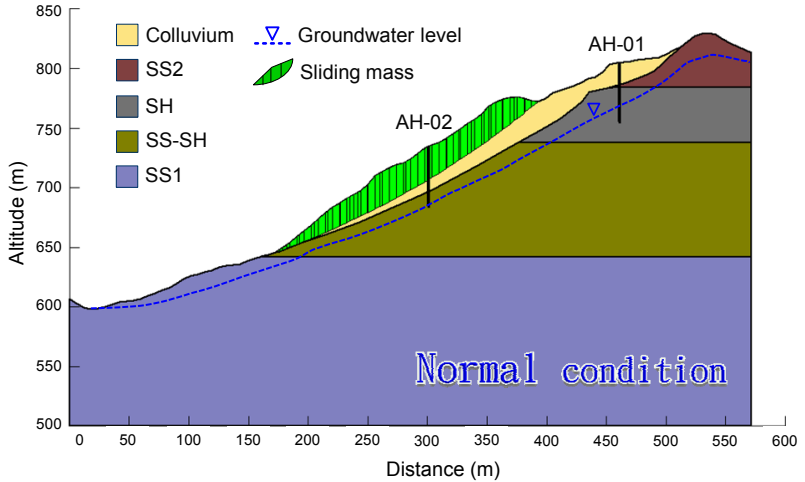

Figure 10. Analysis results under normal condition

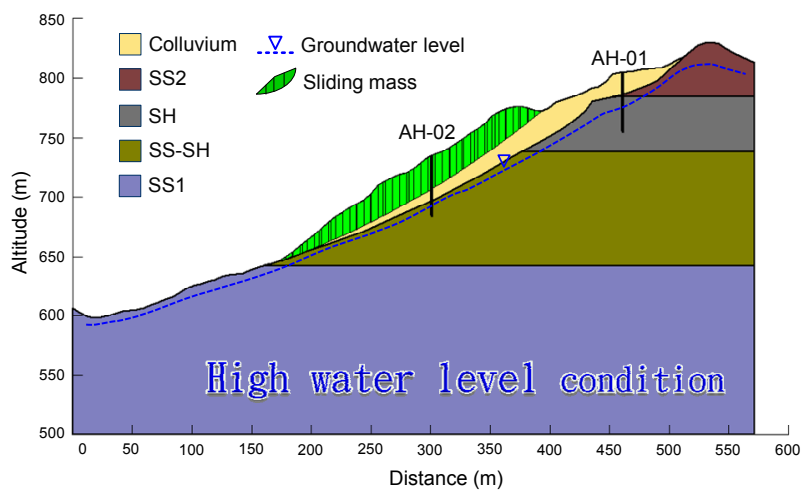

Figure 11. Analysis results under high water level condition

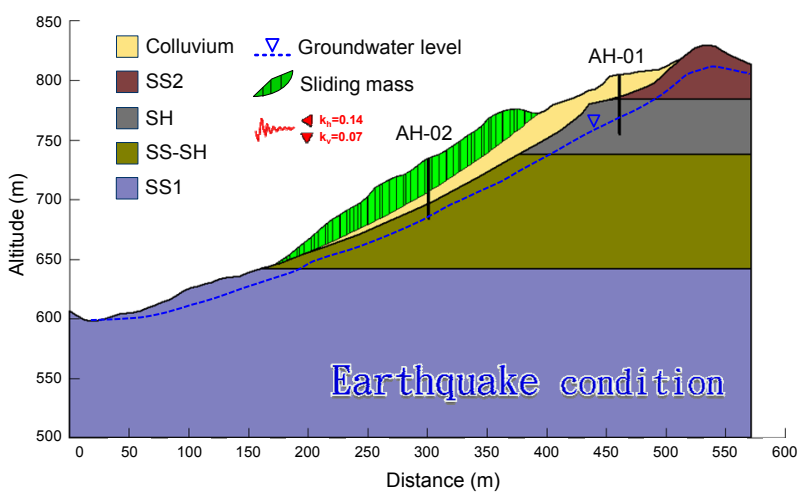

Figure 12. Analysis results under earthquake condition

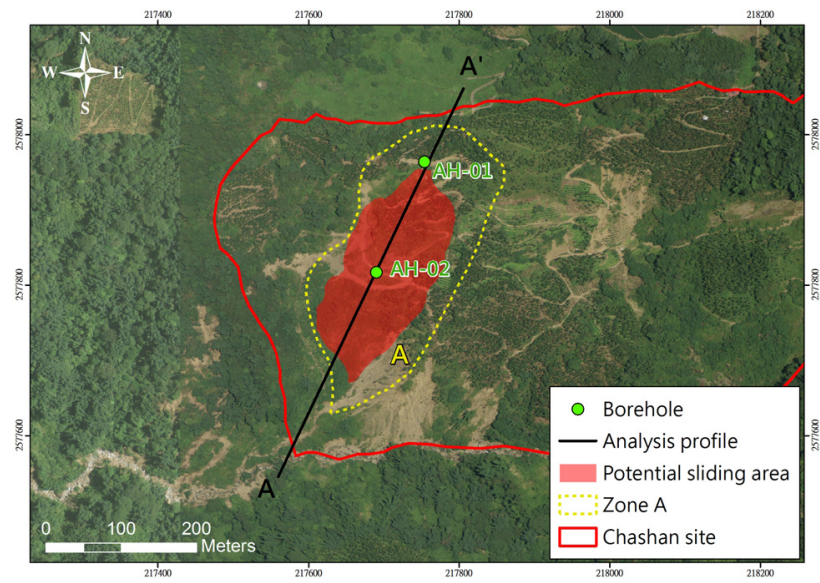

Figure 13. Potential sliding area under earthquake condition

\section{DETERMINISTIC THRESHOLDS}

\subsection{Groundwater-level threshold}

Based on the above analysis results, this study sets different conditions by water level elevation, shown in Figure 14, in order to explore the mechanism of rainfall-induced landslide. With the water level under normal condition as a benchmark, the water level in each scenario is raised 5 meters upwards and the water level is no more than the ground surface. Figure 15 shows the relationship between the water level rise and F.S. at AH-02 borehole. The results show that when the water level rises more than 10 meters, the F.S. will start to decrease. The F.S. will be reduced to 1.0 when the water level is raised over 25 meters, which shows that the A4 potential sliding mass may collapse at this time. Observation data show that the change of water level at $\mathrm{AH}-02$ is about 0.3 meters (marked as $\star$ in the Figure 15), which is not enough to cause the A4 potential sliding mass to collapse.

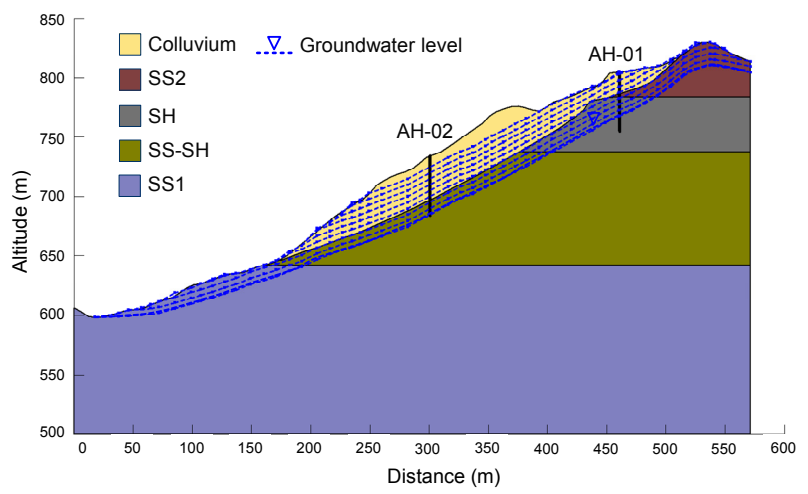

Figure 14. Groundwater level setting under different conditions

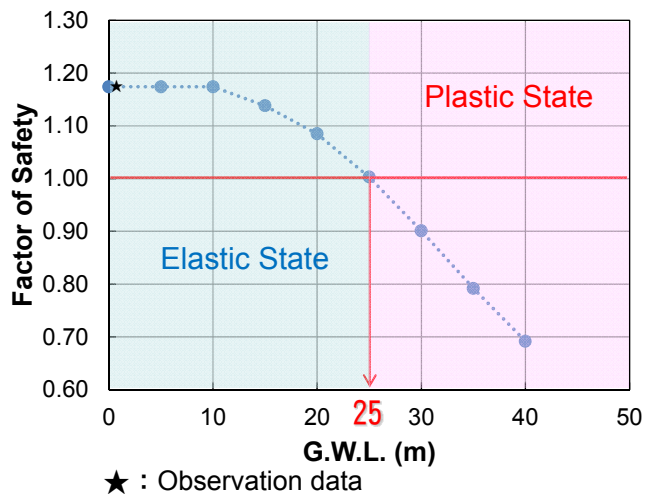

Figure 15. Variation of F.S. with groundwater level

\subsection{PGA threshold}

Based on the above analysis results, this study sets different conditions by PGA, shown in Figure 16, in order to explore the mechanism of seismic-induced landslide. The PGA in each scenario is from 0 to 560 gal. Figure 17 shows the relationship between PGA and F.S. in zone A. The results show that the F.S. of A4 potential sliding mass decreases with increasing PGA. The F.S. will be reduced to 1.0 when the PGA is over 160 gal, which shows that the A4 potential sliding mass may collapse at this time. Observation data show that the PGA of zone A at Chiayi Earthquake (November 22, M5.5) is between 26 and 48 
gal (marked as $\star$ in the Figure 17), which is not enough to cause the A4 potential sliding mass to collapse.

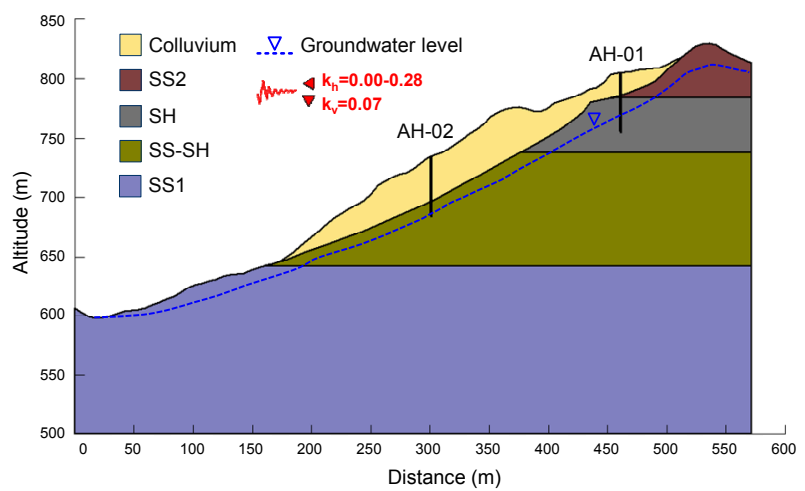

Figure 16. PGA setting under different conditions

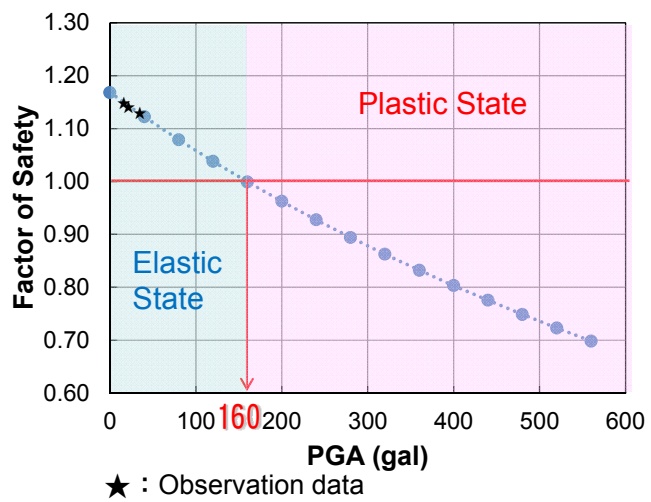

Figure 17. Variation of F.S. with PGA

\section{CONCLUSIONS}

A list of conclusions and suggestions is summarized below as a reference for the reader:

1. According to the results of geological survey, there are two to four potential sliding masses in zone A, B and C, respectively. It is recommended to assess the different conditions of the potential sliding mass, and pay attention to its activity.

2. The results of scenario simulation show that: (1) In the normal and high water level scenarios, the safety factor obtained in each zone is greater than 1.0, and the initial judgment belongs to the relatively stable state; (2), In the earthquake scenario, the A4 and Auto masses in zone A may collapse, of which the volume of A4 collapse is larger, about $917,729 \mathrm{~m}^{3}$.

3. Through the deterministic threshold assessment, when the water level in zone A rises more than 25 meters or the PGA exceeds $160 \mathrm{gal}$, it is possible to cause the collapse of A4 potential sliding mass.

4. The result of the study will contribute that the complex phenomenon between the stability of landslides and hydrogeological conditions can be revealed and clarified through the detailed study on the hydrogeological investigation, observation and the numerical simulation.

\section{ACKNOWLEDGEMENTS}

The authors wish to acknowledge the financial support of the Taiwan Central Geological Society. We are especially thankful to C.P. Lin and Vvn W. Chao, the Prof. of the Disaster Prevention \& Water Environment Research Center at National Chiao Tung University. Finally, to all of the colleagues at Sinotech Engineering Consultants, Inc., thank you for your support and hard work.

\section{REFERENCES}

Central Geological Survey, MOEA, 2010-2012. Project of investigation and analysis for geologically sensitive areas under the program of national land preservation - geological suscepitability analysis in areas left intact by Morokot typhoon, Taipei, Taiwan. (in Chinese)

Central Geological Survey, MOEA, 2013-2015. Project of investigation and analysis for geologically sensitive areas under the program of national land preservation - geological suscepitability analysis in damage area struck by Morokot typhoon, Taipei, Taiwan. (in Chinese)

Chung, M.C., Tan, C. H., Chen, C.H., 2017. Local rainfall thresholds for forecasting landslide occurrence: Taipingshan landslide triggered by Typhoon Saola, Landslides, 14(1), 19-33.

Construction and Planning Agency, MOI, 2011. Seismic Design Specifications and Commentary of Buildings, Taipei, Taiwan. (in Chinese) 